\title{
GERMINAÇÃO DE SEMENTES DE DIVERSOS GENÓTIPOS DE MILHO TROPICAL (ZEA MAYS L.) EM DIFERENTES TEMPERATURAS ${ }^{1}$
}

\author{
CLEVERSON SILVEIRA BORBA, RAMIRO VILELA DE ANDRADE, \\ JOÅO TITO DE AZEVEDO, CLAUDINEI ANDREOLI \& ANTONIO ALVARO CORSETE PURCINO
}

\begin{abstract}
RESUMO - Sementes de diversos genótipos de milho foram postas para germinar em temperaturas constantes de $5,10,15,20,25,30,35,40$ e $45^{\circ} \mathrm{C}$, com o objetivo de determinar as temperaturas favoráveis à germinação. As sementes foram analisadas através do teste de germinação e do índice de velocidade de germinação. Dos resultados obtidos observou-se que para as sementes das variedades BR 106, BR 451, híbrido duplo BR 201 e populações CMS 14 e CMS 54, a faixa de temperatura mais favorável para germinação situou-se entre $15^{\circ} \mathrm{C}$ e $35^{\circ} \mathrm{C}$. Para as populações CMS 04 e CMS 28 a faixa de temperuatura mais favorável situou-se entre $20^{\circ} \mathrm{C}$ a $35^{\circ} \mathrm{C}$ e de $10^{\circ} \mathrm{C}$ a $35^{\circ} \mathrm{C}$, respectivamente. Para todos os genótipos estudados, a temperatura de $35^{\circ} \mathrm{C}$ foi a que proporcionou germinação mais rápida, não ocorrendo germinação nas temperaturas de $5^{\circ} \mathrm{C} \mathrm{e} 45^{\circ} \mathrm{C}$.A população $\mathrm{CMS} 28$ pode ser um boa fonte de genes para tolerancia à baixa temperatura como $10^{\circ} \mathrm{C}$, e a variedade $\mathrm{BR} 451$ à alta temperatura como $40^{\circ} \mathrm{C}$.
\end{abstract}

Termos para indexação: Zea mays L., sementes, germinação, temperatura.

GERMINATION OF TROPICAL MAIZE (ZEA MAYS L.) GENOTYPES SEEDS AT DIFFERENT TEMPERATURES

\begin{abstract}
Seeds of tropical maize genotypes were germinated at constant temperatures, ranging from $5^{\circ} \mathrm{C}$ to $45^{\circ} \mathrm{C}$, in order to determine the most favorable temperature for germination. Analysis were performed according to the standard germination and speed of germination tests. Varieties BR 106 and BR 451, the double hybrid BR 201 and populations CMS 14 and CMS 54 showed optimal germination between $15^{\circ} \mathrm{C}$ and $35^{\circ} \mathrm{C}$. population CMS and variety BR 126 germinated better between $20^{\circ} \mathrm{C}$ and $35^{\circ} \mathrm{C}$, and population CMS 28 btween $10^{\circ} \mathrm{C}$ and $35^{\circ} \mathrm{C}$. All genotypes had highest speed of germination at $35^{\circ} \mathrm{C}$ and no germination was recorded at $5^{\circ} \mathrm{C}$ and $45^{\circ} \mathrm{c}$. Population CMS 28 may be a good gene source for tolerance to temperature as low as $10^{\circ} \mathrm{C}$, and variety BR 451 to temperature as high as $40^{\circ} \mathrm{C}$.
\end{abstract}

Index terms: Zea mays L., seeds, germination, temperature.

\section{INTRODUÇÃO}

Em determinadas regiões do País o milho tem sido cultivado durante todo o ano. Entretanto, devido à inexistência de informações sobre a limitação de temperatura para a semeadura, muitas lavouras tem sido comprometidas em função da inadequada população de plantas. Para uma boa germinação as sementes requerem água, oxigênio e temperatura favorável. Dessas três necessidades apenas temperatura não é controlável no campo. Por isso, torna-se necessário o conhecimento das temperaturas favoráveis para germinação, dos diferentes cultivares, para que problemas de estabelecimento de população inicial de plantas (estande), que vem ocorrendo todos os anos com a cultura do milho sejam minimizados.

Delouche (1953), estudando a influência da temperatura

\footnotetext{
${ }^{1}$ Aceito para publicação em 12.07.95.

Trabalho financiado pela Fundação de Amparo a Pesquisa de Minas Gerais - FAPEMIG.

${ }^{2}$ Pesquisadores do Centro Nacional de Pesquisa de Milho e SorgoEMBRAPA, Caixa Postal 151, CEP 35701-970, Sete Lagoas, MG.
}

na germinação de sementes milho, encontrou que o máximo de germinação foi obtido à $30^{\circ} \mathrm{C}$ e que a germinação nesta temperatura, foi mais rápida do que em temperaturas alternadas de $20-30^{\circ} \mathrm{C}$.

Em um trabalho onde foram estabelecidas as temperaturas cardinais para diversas espécies, Delouche, citado por Popinigis (1977), estabeleceu que para o milho a germinação é mínima em temperaturas de $8^{\circ} \mathrm{C}$ e $10^{\circ} \mathrm{C}$ e máxima em temperaturas entre $32^{\circ} \mathrm{C}$ a $35^{\circ} \mathrm{C}$, enquanto que nas temperaturas entre $40^{\circ} \mathrm{C} \mathrm{e} 44^{\circ} \mathrm{C}$ não ocorre germinação.

Riley (1981a, 1981b), estudando a emergência de plântulas de milho nos trópicos, concluiu que os baixos índices foram em parte devido à altas temperaturas do solo. Em geral, as temperaturas ótimas para germinação variaram de $26^{\circ} \mathrm{C}$ a $29^{\circ} \mathrm{C}$. Observou ainda que a taxa da síntese de proteína à $41^{\circ} \mathrm{C}$ foi reduzida a um terço do que nas sementes embebidas a $28^{\circ} \mathrm{C}$, causado pelo bloqueio da síntese de mRNA.

Eagles \& Hardacre (1979), em um estudo sobre a germinação e a emergência de plântulas de diversos genótipos de milho, provenientes da população Pool 5, encontraram uma grande variação genotípica para diversos caracteres uti- 
lizados, e que os melhores genótipos daquela população foram marcadamente superiores aos híbridos utilizados como testemunhas, e concluíram que, a população Pool é uma fonte importante para melhorar a tolerância de germinação de sementes de milho à baixas temperaturas.

Blacklow (1972), estudando a influência da temperatura na germinação de sementes de milho, encontrou que o alongamento da raiz primária e do coleóptilo foram maiores na temperatura de $30^{\circ} \mathrm{C}$ e efetivamente cessaram em temperaturas de $9^{\circ} \mathrm{C}$ e $40^{\circ} \mathrm{C}$. O período de tempo para iniciação do crescimento da raiz primária e do coleóptilo foi muito pequeno à temperatura de $30^{\circ} \mathrm{C}$.

Perrier et al. (1967), estudando o efeito da temperatura de germinação na área foliar e produção de $\mathrm{CO}_{2}$ de plântulas de milho, concluiram que a temperatura, durante as primeiras 48 horas, influiu significativamente na relação área foliar/respiração das plântulas, e que a maior temperatura estudada $\left(29^{\circ} \mathrm{C}\right)$ causou um substancial aumento da área foliar e eficiência respiratória.

Nesse sentido, o objetivo do trabalho foi determinar as temperaturas mais favoráveis à germinação de diversos genótipos de milho, oriundos do programa de melhoramento do Centro Nacional de Milho e Sorgo da EMBRAPA.

\section{MATERIAL E MÉTODOS}

O trabalho foi realizado no Centro Nacional de Milho e Sorgo (CNPMS) da EMBRAPA,em Sete Lagoas, MG, localizado a $19^{\circ} 28^{\prime}$ de latitude S e $44^{\circ} 15^{\prime} 08^{\prime \prime}$ de longitude W, no ano de 1994.

Sementes de milho BR 106, BR 126, BR 451, do híbrido BR 201 e das populações CMS 04, CMS 14, CMS 24 e CMS 28 foram analisadas quanto à porcentagem e à velocidade de germinação, em diversas temperaturas.

A germinação das sementes foi realizada utilizando-se o teste de germinação de acordo com as Regras para Análise de Sementes (Brasil, 1992), com temperaturas constantes de $5^{\circ} \mathrm{C}, 10^{\circ} \mathrm{C}, 15^{\circ} \mathrm{C}, 20^{\circ} \mathrm{C}, 25^{\circ} \mathrm{C}, 30^{\circ} \mathrm{C}, 35^{\circ} \mathrm{C}, 40^{\circ} \mathrm{C}$ e $45^{\circ} \mathrm{C}$.

$\mathrm{O}$ índice de velocidade de germinação foi determinado considerando-se plântulas normais com o mínimo de $3 \mathrm{~cm}$ de comprimento e com todas as estruturas essenciais bem desenvolvidas, calculado pelo somatório de plântulas germinadas diariamente, multiplicado pelo inverso do número de dias ocorridos da semeadura à contagem (Maguire, 1962).

O experimento foi analisado utilizando-se um delineamento estatístico inteiramente casualizado, com quatro repetições. Os resultados foram analisados através de análise da variância, com comparação de médias utilizando o teste de
Duncan, a $5 \%$ de probabilidade.

\section{RESULTADOS E DISCUSSÃO}

A germinação e o índice de velocidade de germinação, para os genótipos testados, apresentaram diferenças de resposta às temperaturas, altamente significativas a $1 \%$ de probabilidade pelo teste $\mathrm{F}$ (Tabela 1).

$\mathrm{Na}$ Tabela 2, pode-se observar por meio dos resultados que, alguns dos genótipos acusaram índices de germinação signficativos, até o limite máximo de $35^{\circ} \mathrm{C}$. A partir dessa temperatura, houve um declínio acentuado e significativo na porcentagem de germinação, sendo que na temperatura máxima de $45^{\circ} \mathrm{C}$, bem como na temperatura mínima de $5^{\circ} \mathrm{C}$, a germinação das sementes não ocorreu. Esses resultados estão de acordo com os encontrados por Delouche, citado por Popinigis (1977), quando se estabeleceu as temperaturas cardinais para o milho. Já na temperatura de $5^{\circ} \mathrm{C}$, as sementes iniciaram o processo dẻ germinação com a raiz primária iniciando a protusão, mas cessando seu desenvolvimento com a morte das sementes, da mesma forma como o encontrado por Blacklow (1972) à temperatura de $9^{\circ} \mathrm{C}$.

Destacou-se entre todos os genótipos testados, o CMS 28 que apresentou maior amplitudes de germinação à partir da temperatura de $10^{\circ} \mathrm{C}$ (Tabela 2). Embora a porcentagem de germinação do $\mathrm{BR} 451$ aos $40^{\circ} \mathrm{C}$ tenha sido significativamente inferior às ocorridas na faixa favorável $\left(15^{\circ} \mathrm{C} \mathrm{a}\right.$ $35^{\circ} \mathrm{C}$ ), foi nitidamente superior aos demais genótipos alcançando a germinação de $83 \%$. Isto provavelmente, pode ser explicado por ser o BR 451 de alta qualidade proteíca consumindo menor quantidade de proteína nos processos metabólicos. Segundo Riley (1981a, 1981b) a taxa na síntese de proteína durante a germinação à temperatura de $41^{\circ} \mathrm{C}$ é de $1 / 3(33 \%)$ daquela requerida à temperatura de $28^{\circ} \mathrm{C}$. Com base nessas informações, o BR 451 poderia ser utilizado no melhoramento de plantas, como uma fonte de genes, para o desenvolvimento e obtenção de cultivares com tolerância à altas temperaturas durante a germinação. Da mesma forma o CMS 28 poderia ser usado na obtenção de cultivares com tolerância à baixa temperaturas durante a germinação. Essas informações estão de acordo com Eagles \& Hardacre (1979), que salientaram a população Pool 5 , como sendo uma fonte importante de genes para melhorar a germinação e a emergência das plântulas à baixas temperaturas.

Os resultados acusaram, para a maioria dos genótipos testados, um crescimento gradual e significativo no índice de velocidade de germinação, a partir da temperatura de $10^{\circ} \mathrm{C}$ até $35^{\circ} \mathrm{C}$, quando atingiu o maior índice, declinando para temperaturas mais altas (Tabela 3). Da mesma forma, a temperatura de $35^{\circ} \mathrm{C}$ foi a que proporcionou maior velocida- 
TABELA 1. Resumo da análise de variância dos resultados de germinação e velocidade de germinação das sementes de diversos genótipos de milho, em diferentes temperaturas. EMBRAPA-CNPMS, Sete Lagoas, MG, 1995.

\begin{tabular}{|c|c|c|c|c|c|c|c|c|c|}
\hline \multirow{3}{*}{ Causas da variação } & \multirow{3}{*}{$\begin{array}{l}\text { Graus de } \\
\text { liberdade }\end{array}$} & \multicolumn{8}{|c|}{ Teste F } \\
\hline & & \multicolumn{8}{|c|}{ Genótipos } \\
\hline & & BR 106 & BR 126 & BR 201 & BR 451 & CMS 04 & CMS 14 & CMS 28 & CMS 54 \\
\hline Temperatura (a) & 8 & $744.4^{* *}$ & $657.4^{* *}$ & $423.3^{* *}$ & $618.0^{* *}$ & $282.3^{* *}$ & $473.5^{* *}$ & $740.6^{* *}$ & $182.2^{* *}$ \\
\hline Veloc. germinação (b) & 8 & $450.6^{* *}$ & $720.8^{* *}$ & $617.3^{* *}$ & $1.218 .8^{* *}$ & $469.8^{* *}$ & $696.6^{* *}$ & $198.1^{* *}$ & $293.0^{* *}$ \\
\hline Coeficiente de & (a) & 4.3 & 4.6 & 5.8 & 4.6 & 8.2 & 5.3 & 4.5 & 9.0 \\
\hline Variação (\%) & (b) & 8.0 & 6.5 & 6.9 & 4.8 & 8.4 & 6.3 & 11.7 & 9.9 \\
\hline
\end{tabular}

** Significativo a $1 \%$ de probabilidade

TABELA 2. Germinação (\%) de diversos genótipos de milho em diferentes temperaturas. EMBRAPA-CNPMS. Sete Lagoas, MG, 1995.

\begin{tabular}{|c|c|c|c|c|c|c|c|}
\hline \multirow[t]{2}{*}{ Genótipos } & \multicolumn{7}{|c|}{ Temperaturas } \\
\hline & $10^{\circ} \mathrm{C}$ & $15^{\circ} \mathrm{C}$ & $20^{\circ} \mathrm{C}$ & $25^{\circ} \mathrm{C}$ & $30^{\circ} \mathrm{C}$ & $35^{\circ} \mathrm{C}$ & $40^{\circ} \mathrm{C}$ \\
\hline BR 106 & $70.5 \mathrm{Bd}$ & $86.5 \mathrm{Ac}$ & 89.0Aabc & $89.0 \mathrm{Abc}$ & $82.5 \mathrm{Ad}$ & $87.0 \mathrm{Ac}$ & $60.0 \mathrm{Ccd}$ \\
\hline BR 126 & $80.0 \mathrm{Bc}$ & $75.5 \mathrm{Bd}$ & 89.0Aabc & $92.5 \mathrm{Aab}$ & 87.5Abcd & 93.5 Aab & $56.0 \mathrm{Cd}$ \\
\hline BR 201 & $68.5 \mathrm{Bd}$ & $91.0 \mathrm{Abc}$ & $95.5 \mathrm{Aa}$ & $93.0 \mathrm{Aab}$ & $93.5 \mathrm{Aab}$ & $95.0 \mathrm{Aa}$ & $63.5 \mathrm{Bbc}$ \\
\hline BR 451 & $87.0 \mathrm{Bad}$ & $93.5 \mathrm{Ab}$ & $95.5 \mathrm{Aa}$ & $97.0 \mathrm{Aa}$ & $95.0 \mathrm{Aa}$ & $96.0 \mathrm{Aa}$ & $83.0 \mathrm{Ba}$ \\
\hline CMS 04 & 29.0 Df & $62.5 \mathrm{Be}$ & $87.5 \mathrm{Abc}$ & $85.0 \mathrm{Ac}$ & $85.5 \mathrm{Acd}$ & $88.5 \mathrm{Abc}$ & $45.0 \mathrm{Ce}$ \\
\hline CMS 14 & $83.5 \mathrm{Bbc}$ & $98.0 \mathrm{Aa}$ & $94.0 \mathrm{Aab}$ & $95.0 \mathrm{Aab}$ & $93.5 \mathrm{Aad}$ & $96.5 \mathrm{Aa}$ & $69.0 \mathrm{Cb}$ \\
\hline CMS 28 & $91.0 \mathrm{Aa}$ & $93.5 \mathrm{Aab}$ & $91.5 \mathrm{Aabc}$ & $92.5 \mathrm{Aab}$ & 89.5 Aabc & 91.0Aabc & $48.0 \mathrm{Be}$ \\
\hline CMS 54 & $62.0 \mathrm{Be}$ & $85.5 \mathrm{Ac}$ & $85.0 \mathrm{Ac}$ & $89.0 \mathrm{Abc}$ & 88.5Aabcd & $85.0 \mathrm{Ac}$ & $49.0 \mathrm{Ce}$ \\
\hline
\end{tabular}

Médias seguidas pelas mesmas letras, maiúsculas em linha e minúsculas dentro de coluna, não diferem significativamente a $5 \%$ de probabilidade pelo teste de Duncan.

TABELA 3. Velocidade de germinação (índice) de diversos genótipos de milho em diferentes temperaturas. EMBRAPA-CNPMS. Sete Lagoas, MG, 1995.

\begin{tabular}{|c|c|c|c|c|c|c|c|}
\hline \multirow[t]{2}{*}{ Genótipos } & \multicolumn{7}{|c|}{ Temperaturas } \\
\hline & $10^{\circ} \mathrm{C}$ & $15^{\circ} \mathrm{C}$ & $20^{\circ} \mathrm{C}$ & $25^{\circ} \mathrm{C}$ & $30^{\circ} \mathrm{C}$ & $35^{\circ} \mathrm{C}$ & $40^{\circ} \mathrm{C}$ \\
\hline BR 106 & $1.3 \mathrm{Eab}=$ & $3.8 \mathrm{Da}$ & $7.6 \mathrm{Ca}$ & $9.5 \mathrm{Bbc}$ & $9.5 \mathrm{Bc}$ & $15.1 \mathrm{Ac}$ & $8.4 \mathrm{Cc}$ \\
\hline BR 126 & $1.5 \mathrm{Fa}$ & 3.5 Eab & 7.3 Dab & 10.1 Bab & 10.6 Bab & $16.6 \mathrm{Aa}$ & $8.5 \mathrm{Cc}$ \\
\hline BR 201 & $1.2 \mathrm{Gab}$ & $4.2 \mathrm{Fa}$ & 7.7 Ea & $9.9 \mathrm{Cab}$ & $11.3 \mathrm{Ba}$ & 16.1 Aab & 8.7 Dc \\
\hline BR 451 & $1.6 \mathrm{Fa}$ & $4.3 \mathrm{Ea}$ & 7.7 Dab & $10.7 \mathrm{Ca}$ & $11.1 \mathrm{Cab}$ & 16.6 Aa & $12.7 \mathrm{Ba}$ \\
\hline CMS 04 & $0.5 \mathrm{Fb}$ & $2.8 \mathrm{~Eb}$ & $6.7 \mathrm{Db}$ & $9.0 \mathrm{Cc}$ & 10.3 Bbc & $14.9 \mathrm{Ac}$ & $8.4 \mathrm{Cc}$ \\
\hline CMS 14 & $1.6 \mathrm{Ea}$ & 4.4 Da & $7.5 \mathrm{Cb}$ & 10.2 Bab & $10.7 \mathrm{Ab}$ & 16.1 Aab & $10.3 \mathrm{Bb}$ \\
\hline CMS 28 & $1.8 \mathrm{Ea}$ & 4.2 Da & $7.8 \mathrm{Ca}$ & 10.1 Bab & 10.7 Bab & $15.4 \mathrm{Abc}$ & $8.3 \mathrm{Ccd}$ \\
\hline CMS 54 & 1.2 Eab & 3.9 Da & 7.0 Cab & 9.9 Bab & 10.6 Bab & $14.6 \mathrm{Ac}$ & $7.5 \mathrm{Cd}$ \\
\hline
\end{tabular}

Médias seguidas pelas mesmas letras, maiúsculas em linha e minúsculas dentro de coluna, não diferem significativamente a $5 \%$ de probabilidade pelo teste de Duncan. 
de de germinação e a que se manteve dentro de todas as faixas de temperaturas mais favoráveis para a germinação.

Para todos os genótipos estudados, não houve germinação à $45^{\circ} \mathrm{C}$, e as sementes se apresentaram deterioradas. Estes resultados coincidiram, em parte com os encontrados por Delouche (1977), quando esse afirmou que na faixa de $40^{\circ} \mathrm{C}$ a $44^{\circ} \mathrm{C}$ não ocorre germinação, entretanto ocorreu um contraste, já que a média de germinação dos materiais estudados foi de $59,1 \%$ à $40^{\circ} \mathrm{C}$. Por outro lado, as faixas mais favoráveis para germinação encontradas de $10^{\circ} \mathrm{C}$ a $35^{\circ} \mathrm{C}, 15^{\circ} \mathrm{C}$ a $35^{\circ} \mathrm{C}$ e de $20^{\circ} \mathrm{C}$ a $35^{\circ} \mathrm{C}$, para os diferentes genótipos estudados, demonstraram a existência de uma alta sensibilidade genética ao fator temperatura.

\section{CONCLUSÕES}

- A faixa de temperatura mais favorável para a germinação da cultivar BR 451 e híbrido BR 201 foi de $15^{\circ} \mathrm{C}$ a $35^{\circ} \mathrm{C}$ e para a população CMS 28 foi de $10^{\circ} \mathrm{C}$ a $35^{\circ} \mathrm{C}$.

- Para a maioria dos genótipos estudados, a germinação foi mais rápida à temperatura de $35^{\circ} \mathrm{C}$, não ocorrendo germinação nas temperaturas de $5^{\circ} \mathrm{C}$ e $45^{\circ} \mathrm{C}$.

- A população CMS 28 pode ser uma boa fonte de genes para tolerância à temperatura baixa como $10^{\circ} \mathrm{C}$ e o cultivar BR 451 à temperatura alta como $40^{\circ} \mathrm{C}$.

\section{REFERÊNCIAS}

BLACKLOW, W. M. Influence of temperature on germination and elongation of the radicle and shoot of corn (Zea mays L.) Crop Science. 12 (5): 647-50. 1972.

BRASIL, Ministério da Agricultura. Regras para Análise de Sementes. Brasília, MA-SNAD-LANARV, 1992. 365 p.

DELOUCHE, J.C. Influence of moisture and temperature levels on the germination of corn, soybean and watermelons. Association of Official Seed Analyst., v.43 (1):117-26. 1953.

DELOUCHE, J.C. Temperature relations of germination. Seed Technology Laboratory. Agronomy Department. Mississippi State University, 1977. 15p.

EAGLES, H.A. \& HARDACRE, A.K. Genetic variation in maize (Zea mays L.) for germination and emergence at $10^{\circ} \mathrm{C}$. Euphytica, 28 (1):287-95. 1979

MAGUIRE, J.D. Speed of germination-aid in selection and evaluation for, seedling emergence and vigor. Crop Science, 2 (2): 176-7, 1962.

PERRIER, E.R.; TWERSKY, M.; PETERS, D.B.; GYLYS, V. Effect of germination temperature on surface area and $\mathrm{CO}_{2}$ production of corn seedlings. Agronomy Journal, 59(2):133$6,1967$.

POPINIGIS, F. Fisiologia da semente. Brasília, AGIPLAN, 1977. $289 \mathrm{p}$.

RILEY, G.J.P. Effects of high temperature on the germination of maize (Zea mays L.). Planta, 151 (1): 68-74. 1981.a.

RILEY, G.J.P. Effect of high temperature on protein synthesis during germination of maize (Zea mays L.). Planta, 151 (1):7580. 1981.b. 